BMJ Open

Diabetes

Research

\& Care

\title{
Early treatment revisions by addition or switch for type 2 diabetes: impact on glycemic control, diabetic complications, and healthcare costs
}

\author{
Phil Schwab, ${ }^{1}$ Vishal Saundankar, ${ }^{1}$ Jonathan Bouchard, ${ }^{2}$ Neil Wintfeld, ${ }^{2}$ \\ Brandon Suehs, ${ }^{1}$ Chad Moretz, ${ }^{1}$ Elsie Allen, ${ }^{2}$ Antonio DeLuzio ${ }^{2}$
}

To cite: Schwab $\mathrm{P}$ Saundankar V, Bouchard J, et al. Early treatment revisions by addition or switch for type 2 diabetes: impact on glycemic control, diabetic complications, and healthcare costs. BMJ Open Diabetes Research and Care 2016;4:e000099.

doi:10.1136/bmjdrc-2015000099

Received 3 March 2015 Revised 23 November 2015 Accepted 25 December 2015

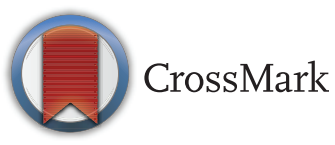

${ }^{1}$ Comprehensive Health Insights, Inc., A Humana Company, Louisville,

Kentucky, USA

${ }^{2}$ Novo Nordisk Inc.,

Plainsboro, New Jersey, USA

Correspondence to Dr Phil Schwab;

pschwab@humana.com

\section{ABSTRACT}

Background: The study examined the prevalence of early treatment revisions after glycosylated hemoglobin $(\mathrm{HbA1c}) \geq 9.0 \%(75 \mathrm{mmol} / \mathrm{mol})$ and estimated the impact of early treatment revisions on glycemic control, diabetic complications, and costs.

Research design and methods: A retrospective cohort study of administrative claims data of plan members with type 2 diabetes and $\mathrm{HbA} 1 \mathrm{c} \geq 9.0 \%$ $(75 \mathrm{mmol} / \mathrm{mol})$ was completed. Treatment revision was identified as treatment addition or switch. Glycemic control was measured as $\mathrm{HbA} 1 \mathrm{C}$ during 6-12 months following the first qualifying $\mathrm{HbA1c} \geq 9.0 \%$ (75 mmol/ $\mathrm{mol}$ ) laboratory result. Complications severity (via Diabetes Complication Severity Index (DCSI)) and costs were measured after 12, 24, and 36 months. Unadjusted comparisons and multivariable models were used to examine the relationship between early treatment revision (within 90 days of $\mathrm{HbA} 1 \mathrm{c}$ ) and outcomes after controlling for potentially confounding factors measured during a 12-month baseline period.

Results: 8463 participants were included with a mean baseline $\mathrm{HbA} 1 \mathrm{c}$ of $10.2 \%(75 \mathrm{mmol} / \mathrm{mol})$. Early treatment revision was associated with greater reduction in $\mathrm{HbA1c}$ at $6-12$ months $(-2.10 \%$ vs $-1.87 \% ; p<0.001)$. No significant relationship was observed between early treatment revision and DCSI at 12,24 , or 36 months $(p=0.931, p=0.332$, and $\mathrm{p}=0.418$ ). Total costs, medical costs, and pharmacy costs at 12,24 , or 36 months were greater for the early treatment revision group compared with the delayed treatment revision group (all $p<0.05$ ).

Conclusions: The findings suggest that in patients with type 2 diabetes mellitus, treatment revision within 90 days of finding an $\mathrm{HbA1c} \geq 9.0 \%$ is associated with a greater level of near-term glycemic control and higher cost. The impact on end points such as diabetic complications may not be realized over relatively short time frames.

\section{INTRODUCTION}

Type 2 diabetes mellitus is a disease characterized by hyperglycemia due to impaired insulin secretion and reduced sensitivity to

\section{Key messages}

- Even though all study participants had a record of glycosylated hemoglobin ( $\mathrm{HbA1c}) \geq 9 \%$, a minority $(34.7 \%)$ added a treatment or switched treatments within 90 days of the $\mathrm{HbA} 1 \mathrm{C} \geq 9 \%$ laboratory test.

- Early treatment revision by addition or switch was associated with a greater level of near-term glycemic control.

- Early treatment revision had no impact on end points such as diabetic complications. However the effect of this intervention may not be realized over relatively short time periods.

- Future studies should extend the observation period for outcomes.

insulin's effects. In 2012, 29.1 million people, approximately $9.3 \%$ of the US population, had diabetes with the highest percentages of individuals with diabetes aged 65 and older. ${ }^{1}$ Patients with type 2 diabetes are at risk for a range of complications as the disease progresses, including retinopathy, nephropathy, neuropathy, and peripheral vascular disease, which predispose to limb amputation. Adults with diabetes are also at increased risk for cardiovascular disease and stroke. ${ }^{1-4}$ Complications can significantly increase the cost incurred by patients and payers. For example, the American Diabetes Association estimated total healthcare costs (direct and indirect) for 2012 at $\$ 245$ billion for patients with diabetes, a $41 \%$ increase from the previous estimate of $\$ 174$ billion (adjusted to 2007 dollars). ${ }^{5} 6$

The American Diabetes Association's recent addition of glycosylated hemoglobin (HbA1c) to fasting plasma glucose and oral glucose tolerance testing as an alternative method to diagnose diabetes may increase the rate of early detection of diabetes because it is more convenient. HbAlc has been identified as the strongest predictor of 
hospitalisation in persons with diabetes, in that better glycemic control is associated with fewer hospitalisations and lower inpatient costs when hospitalisations do occur. $^{78}$

The American Diabetes Association recommends an HbAlc target $<7 \%$ (53 mmol $/ \mathrm{mol})$. An HbAlc level $\geq 7 \%$ (53 mmol $/ \mathrm{mol}$ ) represents less than ideal glycemic control indicating that treatment initiation or modification may be needed. ${ }^{9}$ Glycemic targets such as HbAlc should be individualized to accommodate patient preference, age, risk for hypoglycemia, and other factors. Therefore, HbAlc goals can vary from patient to patient. While an HbAlc above $7 \%$ (53 mmol/mol) might not require a treatment revision by way of treatment addition or switch in real-world practice, an HbAlc $\geq 9 \%(75 \mathrm{mmol} / \mathrm{mol})$ is certainly indicative of extremely poor control for which aggressive therapy with insulin is usually recommended. ${ }^{10}$ Delayed treatment revision in cases of uncontrolled hyperglycemia can unnecessarily place patients at increased risk for negative clinical outcomes, increased healthcare utilization, and higher costs.

The goal of this study was to evaluate the prevalence of delayed pharmacological treatment revisions in cases where $\mathrm{HbA1c} \geq 9.0 \%$ ( $75 \mathrm{mmol} / \mathrm{mol}$ ) was observed, and to estimate the impact of early treatment revision on glycemic control, diabetic complications, and healthcare costs.

\section{METHODS}

\section{Data source}

The retrospective study was conducted using member enrolment, medical and pharmacy claims, and laboratory results from a large national health plan (Humana Inc, Louisville, Kentucky, USA). Medical claims represented services and products paid through a member's medical benefit at any location, including inpatient, outpatient, or other setting. Pharmacy claims represented services and products paid for through a member's pharmacy benefit at any pharmacy location or setting. Members included in the current study were Medicare Advantage or fully insured Commercial plan members with both medical and pharmacy benefits. Humana is a national health plan with the majority of plan members residing in the southern and midwestern areas of the USA.

\section{Participant selection}

Health plan members with type 2 diabetes were identified on the basis of the presence of one or more medical claims with qualifying International Classification of Diseases, Ninth Revision, Clinical Modification (ICD-9-CM) code $250 . \times 0$ or $250 . \times 2$ in the primary position, or two or more medical claims where the qualifying codes were observed in the secondary position. Participants with diabetes were also identified on the basis of medication proxy (two or more prescription claims for oral antidiabetic medications or a glucagonlike peptide-1 receptor agonist). Patients with type 2 diabetes with an $\mathrm{HbAlc} \geq 9.0 \%(75 \mathrm{mmol} / \mathrm{mol})$ between 1 January 2008 and 31 December 2009 were identified on the basis of laboratory results data using Logical Observation Identifiers Names and Codes (LOINC) 17855-8, 4549-2, 17856-6, 4548-4, 41995-2, 43150-2, 55454-3, 62388-4, 59261-8, and 71875-9. Invalid HbA1c results (eg, text results) and physiologically nonplausible HbAlc values $(<2.0 \%$ and $>22.0 \%)$ were excluded from the laboratory results data set during initial participant selection and data cleaning procedures. Date of first observed HbAlc $\geq 9.0 \%(75 \mathrm{mmol} /$ $\mathrm{mol})$ were assigned as the index date. Participants with type 2 diabetes and $\mathrm{HbAlc} \geq 9.0 \%(75 \mathrm{mmol} / \mathrm{mol})$ were required to have 12 months of preindex and 36 months of postindex continuous enrolment. Members aged less than 18 or greater than 90 years, and members with a diagnosis of type 1 diabetes mellitus (ICD-9-CM code $250 . \times 1$ or $250 . \times 3)$ or gestational diabetes $(648.8)$ or pregnancy $(630 . \times x-679 . \times x$ or v22.×-v24. $\times$ ) were excluded from the study cohort.

\section{MEASURES}

\section{Baseline measures}

The 12-month preindex measurement period was used to measure baseline demographics and clinical characteristics. Age, gender, race/ethnicity, and geographic region were determined for each participant on the basis of the health plan enrollment data. The baseline Deyo-Charlson Comorbidity Index (DCI) score, Diabetes Complication Severity Index (DCSI) score, number of physician office visits and number of total pharmacy claims were calculated for all members over the 12-month preindex period. The DCI uses 17 categories of comorbidity to calculate a score that reflects a cumulative increased likelihood of 1-year mortality. ${ }^{11}$ The DCI score can range from 0 to 33 and was calculated on the basis of ICD-9 diagnosis codes and associated weights for included medical conditions. Diagnoses were included in the calculation of the DCI if they met the following criteria: (1) diagnosis present on an inpatient's hospitalization claims; or (2) diagnosis present on two or more outpatient medical claims at least 30 days apart. ${ }^{12}$ The DCSI was developed to predict adverse outcomes including hospitalization and mortality based on the number and severity of complications associated with diabetes, and is based on a summary score derived from diagnostic and laboratory data. A recent implementation of the DCSI in a managed care setting demonstrated that a modified version of the index omitting laboratory data can be used to explain concurrent medical costs. In this study, DCSI was determined on the basis of diagnosis codes only with the laboratory components of the nephropathy category score omitted. ${ }^{13}$ The number of physician office visits was calculated as the total number of medical claims for 
an outpatient office encounter based on the place of treatment codes, and the number of pharmacy claims was measured as the total count of unique pharmacy claims for each member.

\section{Treatment revision}

For treatment revisions, only pharmacological treatment additions and switches were considered. Lifestyle changes could not be measured and were not considered. Treatment modifications by dose escalation were not considered for the study definition of treatment revision. Addition or switch in diabetes therapy was defined as the addition of a new treatment, or a switch in treatment relative to the baseline diabetic treatment regimen. Baseline diabetic treatment was determined on the basis of the 90-day period immediately preceding the index date. A minimum of 14 days of treatment prior to the index date were required and the treatment had to overlap the index date in order to be considered as part of the baseline treatment regimen. Diabetic treatment addition was operationalized as the observation of a prescription claim for a new antidiabetic medication during the follow-up period. In order to be counted as an addition, the new medication was required to overlap with all baseline medications for at least 1 day and the patient was required to have at least one claim for all preindex medications after the new medication was observed. Changes from monotherapy to a combination antidiabetic product were also considered addition of treatment. Monotherapy was defined as treatment with a single agent. Fixed-dose combination products containing more than one antidiabetic agent were considered as two mediciations. Diabetic treatment switch was defined as discontinuation of baseline treatment (refill gap $\geq 90$ days) and observation of a prescription claim for a new antidiabetic medication. The number of days to treatment revision was calculated as the number of days between the index date and first observed treatment addition or switch date. Participants were segmented into two groups for comparison: patients with early treatment revision (within 90 days of index date) and patients with delayed or no treatment revision. For participants with early treatment revision, diabetic treatment patterns were examined on the basis of pharmacy claims data.

\section{Health-related outcomes}

Key health-related outcome measures during the follow-up period were HbAlc, DCSI score, and healthcare costs. HbA1c results were examined, as available, for members with a follow-up HbA1c laboratory result recorded during months 6-12 of postindex follow-up. DCSI was determined at 12-month, 24-month, and 36-month postindex measurement periods. All-cause healthcare costs were determined on the basis of financial data associated with medical and pharmacy claims. Medical expenditures were calculated as the sum of actual paid amounts associated with medical claims during the measurement period. Pharmacy costs were calculated as the sum of actual paid amounts associated with adjudicated pharmacy claims. All cost amounts included both plan-paid and member-paid components. Total healthcare costs were defined as the sum of medical and pharmacy costs. Healthcare costs were measured for 12-month, 24-month, and 36-month measurement periods. All cost data were adjusted to 2012 dollars using the medical care component of the Consumer Price Index.

\section{Statistical analysis}

Bivariate statistical tests were used to compare baseline demographics, clinical characteristics, and outcome measures for patients with early treatment revision and patients without early treatment revision. $T$ tests, $\chi^{2}$, and Wilcoxon rank-sum tests were used on the basis of the type of data being examined, as appropriate. Multivariable regression models were used to examine the relationship between early treatment revision and health-related outcomes after controlling for potentially confounding factors. For the cost, HbAlc, and DCSI data, generalized linear models with $\gamma$ variance and log-link variance functions were fit. Control variables included in the models were age, gender, geographic region, race, baseline HbAlc value, baseline DCI and DCSI scores, baseline number of physician office visits, and number of pharmacy claims. Prior to fitting the multivariable models, outliers (observed values outside a range equal to \pm 4 SDs from the sample mean) were excluded from the model data set.

All data analyses for this study were conducted using the statistical analysis plan as a guide. All analyses of data were conducted using SAS V.9.2. The a priori $\alpha$ level for all inferential analyses was set at 0.05 . The study protocol was reviewed and approved by an independent Institutional Review Board prior to initiation of the analysis (Schulman Associates IRB; Cincinnati, Ohio, USA).

\section{RESULTS}

The participant identification process is summarised in table 1. A total of 8463 health plan members with type 2 diabetes, an index HbAlc $\geq 9.0 \%(75 \mathrm{mmol} / \mathrm{mol})$, and meeting the study inclusion and exclusion criteria were identified. Patient characteristics for the overall study group and with segmentation by early and delayed treatment revision are presented in table 2. Participants overall were in the majority male $(52.1 \%)$ and had a mean (SD) HbAlc of $10.2 \%(1.2 ; 88 \mathrm{mmol} / \mathrm{mol}$ (13) at index. Mean (SD) age for study participants overall was 66.4 (10.8; see table 2). Insulin treatment was reported for $33.0 \%$ of participants during the preindex period. Mean (SD) time to treatment revision was 532 (456) days for the overall sample. Median time to treatment revision was 456 days. Approximately $34.7 \%$ ( $n=2673$ ) of participants engaged in treatment addition or switch within 90 days (early revision) of laboratory result of $\mathrm{HbAlc} \geq 9.0 \%$ ( $75 \mathrm{mmol} / \mathrm{mol})$. Mean and median times 
Table 1 Sample identification and attrition summary

\begin{tabular}{|c|c|c|}
\hline \multirow[b]{2}{*}{ Criteria } & \multicolumn{2}{|c|}{ Remaining } \\
\hline & $\mathbf{n}$ & \\
\hline $\begin{array}{l}\text { Laboratory result indicating } \mathrm{HbA} 1 \mathrm{c} \geq 9 \% \\
\text { (index date) }\end{array}$ & 45865 & 100 \\
\hline Age $<18$ or $>89$ with no enrolment gap & 40980 & 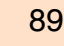 \\
\hline $\begin{array}{l}\text { Continuous enrolment } \geq 12 \text { months } \\
\text { preindex and } \geq 36 \text { months postindex }\end{array}$ & 16553 & \\
\hline $\begin{array}{l}\text { Research eligible members (eg, non-ASO } \\
\text { plan members) }\end{array}$ & 12856 & 2 \\
\hline $\begin{array}{l}\text { Diagnosis of type } 2 \text { diabetes during the } \\
\text { preindex period }\end{array}$ & 11861 & 2 \\
\hline $\begin{array}{l}\text { Exclusion of members with a diagnosis of } \\
\text { T1DM during the study period }\end{array}$ & 8774 & 1 \\
\hline $\begin{array}{l}\text { Primary and secondary diagnosis of type } \\
2 \text { diabetes (medical and Rx claims) }\end{array}$ & 8605 & 1 \\
\hline $\begin{array}{l}\text { No diagnosis of gestational diabetes or } \\
\text { pregnancy during the study period }\end{array}$ & 8496 & 1 \\
\hline $\begin{array}{l}\text { No pharmacy claims over the } 48 \text {-month } \\
\text { study period }\end{array}$ & 8464 & 18 \\
\hline Complete demographic data (ie, gender) & 8463 & 18 \\
\hline Final sample size & 8463 & 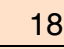 \\
\hline
\end{tabular}

ASO, administrative services only; HbA1c, glycosylated

hemoglobin; T1DM, type 1 diabetes mellitus.

to treatment revisions were 23 and 14 days, respectively, for participants with early treatment revision, while mean and median times to treatment revision were 767 and 939 days, respectively, for participants with addition or switch only after 90 days (delayed revision). Patients with early treatment revision were slightly younger than patients with delayed treatment revision. The difference in age was about 1 year but was statistically significant (see table 2). Patients with early treatment revision also had lower DCI scores and fewer physician office visits during the preindex baseline period (see table 2). Baseline insulin use and multiple diabetic medication treatments at baseline were observed less frequently among patients with an early treatment revision compared with those with delayed treatment revision. Specifically, insulin was claimed in the preindex period by $21.2 \%$ of the participants with early treatment revision and by $38.5 \%$ of the participants with delayed treatment revision. Similarly, multiple antidiabetic medication classes were claimed in the preindex period by $28.0 \%$ of the early treatment revision group and by $53.1 \%$ of the delayed treatment revision group (see table 2). The results suggest that the participants with an early treatment revision might have less aggressive baseline treatment regimens on average than those with a delayed treatment revision.

\section{Patterns of treatment revisions}

The patterns of treatment revisions varied on the basis of the baseline treatment regimen (see table 3). For patients on metformin+sulfonylurea treatment at baseline, the most commonly observed treatment revisions were as follows: switch to basal insulin addition of thiazolidinedione $>$ switch to thiazolidinedione $>$ addition of basal insulin (see table 3). Among patients on sulfonylurea monotherapy at baseline, the most common treatment revisions were as follows: addition of metformin $>$ switch to metformin $>$ switch to basal insulin. For patients on metformin monotherapy at baseline, switch to sulfonylurea and addition of sulfonylurea were the most common treatment revisions.

\section{Follow-up HbA1c and DCSI scores}

A follow-up HbA1c between 6 and 12 months postindex was observed for 6446 patients. Mean follow-up HbAlc for the early treatment revision group was $8.2 \%$ $(66 \mathrm{mmol} / \mathrm{mol})$ compared with $8.5 \% \quad(69 \mathrm{mmol} / \mathrm{mol})$ for the comparison group with delayed treatment revision $(p<0.0001)$. Mean (SD) index to follow-up change in HbAlc was -1.7 (2.0) overall. Mean HbAlc change for the early treatment revision group was -2.1 (2.2) compared with -1.5 (1.9) for the comparison group $(\mathrm{p}<0.0001)$. After controlling for potentially confounding baseline factors in a regression model, early

Table 2 Patient characteristics for overall cohort, patients with early treatment revision (within 90 days of index), and patients with delayed treatment revision

\begin{tabular}{|c|c|c|c|c|c|c|c|}
\hline \multirow[b]{3}{*}{ Age, mean (SD) } & \multirow{2}{*}{\multicolumn{2}{|c|}{$\begin{array}{l}\text { Overall } \\
\mathrm{n}=8463(100.0 \%)\end{array}$}} & \multirow{2}{*}{\multicolumn{2}{|c|}{$\begin{array}{l}\text { Early treatment } \\
\text { revision } \\
\mathrm{n}=2673(31.6 \%)\end{array}$}} & \multirow{2}{*}{\multicolumn{2}{|c|}{$\begin{array}{l}\text { Delayed treatment } \\
\text { revision } \\
\mathrm{n}=5790(68.4 \%) \\
\end{array}$}} & \multirow{3}{*}{$\begin{array}{r}\text { p Value } \\
0.0001\end{array}$} \\
\hline & & & & & & & \\
\hline & 66.4 & $(10.8)$ & 65.7 & $(11.2)$ & 66.8 & $(10.6)$ & \\
\hline Female, n (\%) & 4052 & $(47.9 \%)$ & 1302 & $(48.7 \%)$ & 2750 & $(47.5 \%)$ & 0.3031 \\
\hline $\mathrm{HbA1c}$ at index, mean (SD) & $10.2 \%$ & $(1.2 \%)$ & $10.4 \%$ & $(1.4 \%)$ & $10.1 \%$ & $(1.1 \%)$ & $<0.0001$ \\
\hline $\mathrm{DCI}$ (preindex), mean (SD) & 2.5 & $(2.0)$ & 2.3 & (1.9) & 2.6 & $(2.1)$ & $<0.0001$ \\
\hline Office visits (preindex), mean (SD) & 12.3 & (10.3) & 11.9 & $(10.6)$ & 12.5 & $(10.2)$ & $<0.0001$ \\
\hline Insulin treatment (preindex), n (\%) & 2796 & $(33.0 \%)$ & 567 & $(21.2 \%)$ & 2229 & $(38.5 \%)$ & $<0.0001$ \\
\hline Multiple treatments (preindex), $\mathrm{n}(\%)$ & 3826 & (45.2\%) & 749 & (28.0\%) & 3077 & (53.1\%) & $<0.0001$ \\
\hline
\end{tabular}


Table 3 Patterns of treatment revision for members on common oral antidiabetic medication regimens

\begin{tabular}{|c|c|c|}
\hline Patterns of treatment revision & $\mathbf{n}$ & Per cent \\
\hline \multicolumn{3}{|c|}{ Baseline treatment=metformin/sulfonylurea $(n=418)$} \\
\hline Switch to basal insulin & 99 & 23.7 \\
\hline Add thiazolidinedione & 92 & 22.0 \\
\hline Switch thiazolidinedione & 56 & 13.4 \\
\hline Add basal insulin & 53 & 12.7 \\
\hline Switch non-basal insulin & 29 & 6.9 \\
\hline Add non-basal insulin & 20 & 4.8 \\
\hline All others & 69 & 16.5 \\
\hline \multicolumn{3}{|c|}{ Baseline treatment=sulfonylurea $(n=366)$} \\
\hline Add metformin & 112 & 30.6 \\
\hline Switch metformin & 90 & 24.6 \\
\hline Switch basal insulin & 50 & 13.7 \\
\hline Add thiazolidinedione & 38 & 10.4 \\
\hline Switch thiazolidinedione & 27 & 7.4 \\
\hline Add basal insulin & 17 & 4.6 \\
\hline All others & 32 & 8.7 \\
\hline \multicolumn{3}{|c|}{ Baseline treatment=metformin $(n=342)$} \\
\hline \multicolumn{3}{|c|}{ Addition } \\
\hline Switch sulfonylurea & 136 & 39.8 \\
\hline Add sulfonylurea & 95 & 27.8 \\
\hline Add thiazolidinedione & 27 & 7.9 \\
\hline Add basal insulin & 26 & 7.6 \\
\hline Switch basal insulin & 20 & 5.9 \\
\hline Switch thiazolidinedione & 11 & 3.2 \\
\hline All others & 27 & 7.8 \\
\hline \multicolumn{3}{|c|}{ Baseline treatment $=3+$ orals $(n=197)$} \\
\hline Switch basal insulin & 38 & 19.3 \\
\hline Add basal insulin & 35 & 17.8 \\
\hline Switch metformin & 20 & 10.2 \\
\hline Switch thiazolidinedione & 20 & 10.2 \\
\hline Add metformin & 14 & 7.1 \\
\hline Add non-basal insulin & 9 & 4.5 \\
\hline All others & 61 & 30.9 \\
\hline
\end{tabular}

treatment revision was associated with $\mathrm{HbAlc}$ reduction of $-2.10(95 \% \mathrm{CI}-1.99$ to -2.21$)$ compared with reduction of $-1.87(95 \%$ CI -1.78 to -1.96$)$ in the delayed treatment revision group $(\mathrm{p}<0.001)$. After controlling for baseline characteristics in a regression model, there was no statistically significant relationship observed between early treatment revision and 12-month, 24-month, or 36-month DCSI score $(\mathrm{p}=0.931, \mathrm{p}=0.332$, and $\mathrm{p}=0.418$, respectively). Baseline DCSI was included as a covariate in the DCSI model.

\section{Healthcare costs}

Unadjusted costs for the early treatment revision and the delayed treatment revision groups are presented in table 4. Real total healthcare costs were greater for the early treatment revision group after 12 months $(\$ 10320$ vs $\$ 9935$ ) and after 24 months (\$20 898 vs $\$ 20844$ ), but were less after 36 months (\$29 368 vs $\$ 29526$ ). The differences in unadjusted total healthcare costs were not statistically significant. Unadjusted mean medical costs after 12 months were statistically significantly greater for the early treatment revision group ( $\$ 7327$ vs $\$ 6985$, $\mathrm{p}=0.030$ ) and were greater, but not statistically significant, after 24 months (\$14803 vs \$14633). Medical costs were less, but not statistically significant, after 36 months (\$19978 vs \$19 914). Unadjusted pharmacy costs were lower for the early treatment revision group after 12 months (\$2993 vs \$3027), 24 months (\$6095 vs $\$ 6279, \mathrm{p}=0.025)$, and 36 months (\$8884 vs $\$ 9082)$, but the difference was only statistically significant after 24 months.

In the multivariable adjusted analyses, early treatment revision was associated with greater total healthcare, medical, and pharmacy costs at 12-month, 24-month, and 36-month measurement periods, but the differences appear to lessen over time (see table 4). Total healthcare costs were about $13 \%$ greater for the early treatment revision group after 12 months $(\$ 9766$ vs $\$ 8628$, $\mathrm{p}<0.001)$ but were only about $10 \%$ greater after 24 months $\quad$ \$20 296 vs $\$ 18473, \mathrm{p}<0.001)$, and $6 \%$ greater after 36 months (\$30 409 vs $\$ 28672, \mathrm{p}=0.01)$. Similarly, medical costs were about $13 \%$ greater for the early treatment revision group after 12 months (\$6373 vs $\$ 5623, \mathrm{p}<0.001)$, about $9 \%$ greater after 24 months ( $\$ 13544$ vs $\$ 12415, \mathrm{p}=0.003$ ), and only $6 \%$ greater after 36 months $(\$ 20580$ vs $\$ 19420, \mathrm{p}=0.042)$. Pharmacy costs were about $10 \%$ greater for the early treatment revision group after 12 months $(\$ 2886$ vs $\$ 2614$, $\mathrm{p}<0.001$ ), about $7 \%$ after 24 months (\$5774 vs $\$ 5415$, $\mathrm{p}<0.001$ ), and only $5 \%$ after 36 months ( $\$ 8929$ vs $\$ 8496$, $\mathrm{p}<0.001)$.

\section{DISCUSSION}

Current guidelines recommend treatment modifications after 3 months if glycemic targets are not met. ${ }^{10}$ However, in this study, the overall mean time to treatment revision was 536 days (median time 456 days) and only $34.7 \%$ of study patients with index HbAlc levels $\geq 9 \% \quad(75 \mathrm{mmol} / \mathrm{mol}) \quad$ modified treatment within 90 days. This lack of early treatment revision, sometimes termed clinical inertia, in the majority of cases was surprising given that all cases had HbAlc $\geq 9 \%$ ( $75 \mathrm{mmol} / \mathrm{mol})$. A prior study by Rodondi et $a l^{14}$ identified clinical inertia, as drug class addition or switch, in about $43 \%$ of cases with suboptimal glycemic control compared with $65 \%$ in this study sample. The Rodondi et $a l^{14}$ data were based on 2002-2003 treatment in the Northern California area while this study examined baseline treatments starting in 2008-2009 for patients residing primarily in the Midwest and Southern USA.

In terms of clinical outcomes, the follow-up measure of HbA1c in our study was lower for participants with early treatment revision, but early treatment revision was not related to the measure of DCSI based on claims in the postindex period. The $\mathrm{HbA1c}$ results indicate a possible intermediate-term clinical benefit of earlier 
Table 4 Twelve-month, 24-month, and 36-month unadjusted and adjusted healthcare costs (US\$)

\begin{tabular}{|c|c|c|c|c|c|c|}
\hline & \multicolumn{3}{|c|}{ Unadjusted means (US\$) } & \multicolumn{3}{|c|}{ Adjusted means (US\$) } \\
\hline & \multicolumn{3}{|c|}{ Treatment revision } & \multicolumn{3}{|c|}{ Treatment revision } \\
\hline & Early & Delayed & p Value & Early & Delayed & p Value \\
\hline \multicolumn{7}{|c|}{ 12-month healthcare costs } \\
\hline Total healthcare & $\$ 10320$ & $\$ 9935$ & 0.308 & $\$ 9766$ & $\$ 8628$ & $<0.001$ \\
\hline Medical & $\$ 7327$ & $\$ 6958$ & 0.03 & $\$ 6373$ & $\$ 5623$ & $<0.001$ \\
\hline Pharmacy & $\$ 2993$ & $\$ 3027$ & 0.796 & $\$ 2886$ & $\$ 2614$ & $<0.001$ \\
\hline \multicolumn{7}{|c|}{ 24-month healthcare costs } \\
\hline Total healthcare & $\$ 20898$ & $\$ 20844$ & 0.866 & $\$ 20296$ & $\$ 18473$ & $<0.001$ \\
\hline Medical & $\$ 14803$ & $\$ 14633$ & 0.288 & $\$ 13544$ & $\$ 12415$ & 0.003 \\
\hline Pharmacy & $\$ 6095$ & $\$ 6279$ & 0.025 & $\$ 5774$ & $\$ 5415$ & $<0.001$ \\
\hline \multicolumn{7}{|c|}{ 36-month healthcare costs } \\
\hline Total healthcare & $\$ 29368$ & $\$ 29526$ & 0.822 & $\$ 30409$ & $\$ 28672$ & 0.01 \\
\hline Medical & $\$ 19978$ & $\$ 19914$ & 0.919 & $\$ 20580$ & $\$ 19420$ & 0.042 \\
\hline Pharmacy & $\$ 8884$ & $\$ 9082$ & 0.259 & $\$ 8929$ & $\$ 8496$ & $<0.001$ \\
\hline
\end{tabular}

All costs adjusted to 2012 dollars.

Unadjusted $p$ value from Wilcoxon rank-sum test. Adjusted $p$ value from Wald $\chi^{2}$ test.

Adjusted cost estimates from a generalized linear model using log-link and $\gamma$ variance function. Covariates included in model: age, gender, geographic region, race/ethnicity, baseline Deyo-Charlson score, baseline Diabetes Complication Severity Index score, baseline glycosylated hemoglobin, number of preindex physician office visits, and total number of medications preindex.

treatment revision, which was expected. The DCSI results indicate a lack of clinical benefit or lack of detectable clinical benefit within 36 months of the index HbAlc $\geq 9.0 \% \quad(75 \mathrm{mmol} / \mathrm{mol})$. Future studies should observe clinical outcomes over a longer period of time as 36 months may not be sufficient.

Unadjusted total healthcare costs were similar between groups. The early treatment revision group had greater medical costs at 12 months and lower pharmacy costs at 24 months; however, these unadjusted cost comparisons do not account for potential confounding related to compositional differences (eg, greater comorbidity burden, baseline utilization, and greater age among the delayed treatment revision group). In the adjusted costs models where cumulative costs over time could be compared between groups, early treatment revision was associated with higher costs, possibly due to the use of additional medications and related outpatient services. Although adjusted costs models show higher costs, the actual differential cost of early treatment revision appears to erode as patients are followed year-over-year, suggesting possible future cost savings from early revision. If the study sample were to be observed for a longer period of time (ie, $\geq 3$ years) and the cost trend were to continue linearly and in the same direction, the additional costs associated with early treatment revision could be offset by other cost savings resulting in non-detectable differences in costs or even costs savings for the early treatment revision group. Sufficient data were not available for observations over a longer period of time for this study sample. On the basis of this study's results, costs were actually higher for the early treatment revision group than for the delayed treatment revision group over the 36-month period after adjusting for covariates.

When interpreting the findings, one should consider that no exclusions were placed on the sample based on baseline treatment. All participants were included regardless of antidiabetic treatment, whether there was no antidiabetic treatment, one to two treatments, or many treatments at baseline. Participants already taking more aggressive treatments could be less likely to add a treatment or switch treatments within 90 days, despite a high HbA1c result. For example, a patient already on insulin plus an oral antidiabetic agent has fewer opportunities for treatment revision than a patient only taking a single oral antidiabetic agent. On the basis of a review of the results, the participants with delayed treatment revision were more likely to have a record for insulin or for multiple medications at baseline than the participants with an early treatment revision, suggesting that the participants with an early treatment revision might have less aggressive preindex treatment regimens and a greater opportunity for treatment addition or treatment switch. This artifact could be relevant when interpreting the results of the study or similar studies.

Limitations common to studies using administrative claims data apply to this study. These limitations include lack of certain information in the database (eg, height, weight, and health behavior information) and error in claims coding. This study utilized data from the Humana health plan only, so the results may not be generalizable; although the health plan is a large national plan with members residing in a broad array of geographic regions, the average age for the sample was within expectations given that the health plan has many Medicare Advantage health plan members, and given that the prevalence of type 2 diabetes in the general population is age-related. The study cohort of members identified with $\mathrm{HbAlc} \geq 9.0 \%(75 \mathrm{mmol} / \mathrm{mol})$ was disproportionally African-American and disproportionally from southern USA and therefore may not be representative of the entire US population even considering that 
type 2 diabetes is disproportionally prevalent in southern USA. $^{15}$ The study sample was further limited to those with HbAlc results available in the database. HbA1c results are available for a large number of Humana's health plan members, but not all members with a claim for an HbAlc test had a corresponding laboratory result. Treatment revisions were limited to identification of pharmacological treatment additions or switches for this study. Modifications to dosing are not as clear in claims data, so they were not identified and lifestyle modifications could not be observed because the data were unavailable. Relationships between early or delayed treatment revision and outcomes or costs were established on the basis of statistical associations and temporal relationships. Causal inference cannot be ascertained from this study since it is an observational study utilizing retrospective claims data.

In the study, early treatment revision had effects on glycemic control evidenced by a modestly greater reduction in follow-up HbA1c. Healthcare costs over the short, 36-month time frame were greater among participants in the early treatment revision group when covariates were included to adjust costs. There was no relationship between early treatment revision and diabetic complication severity over the time frame examined. These findings suggest that early treatment revision is associated with a greater level of glycemic control in the immediate term, but the impact on end points such as diabetic complications may not be realized over relatively short time frames of 3 years or less. A longer time period may be needed to observe such impacts of early treatment revision.

Acknowledgements The authors thank Mary Costantino, PhD, for contributions with the writing of the manuscript. Dr Costantino is an employee of Comprehensive Health Insights, a Humana company. The authors also thank Ed Kimball, PhD, for reviewing the manuscript and providing editorial suggestions. Dr Kimball is an employee of Novo Nordisk Inc. The study findings were previously submitted in abstract form and presented in poster form at the International Society for Pharmacoeconomics and Outcomes Research 2014 meeting in Montreal, Canada.

Contributors PS served as the principal investigator for study oversight, contributed to the study design, reviewed data for quality and data analytical results, and also wrote and edited the manuscript. VS contributed to the study design, managed the data, reviewed data for quality, conducted data analysis, reviewed data analytical results, and edited the manuscript. BS contributed to analytical design, reviewed data analytical results, and wrote and edited the manuscript. CM and JB contributed to the study design, reviewed data analytical results, and edited the manuscript. NW, EA, AD contributed to analytical design, reviewed data analytical results, and edited the manuscript.PS is the guarantor of this work.

Funding PS, VS, BS, and CM are employees of Comprehensive Health Insights (CHI) which has received fees from Novo Nordisk Inc, as part of a research collaboration between Humana, Inc and Novo Nordisk Inc, to conduct research.

Competing interests PS, CM, and BS are shareholders of Humana, Inc. JB, NW, EA, and AD are employees and shareholders of Novo Nordisk, Inc.

Ethics approval Schulman \& Associates IRB.

Provenance and peer review Not commissioned; externally peer reviewed.

Data sharing statement No additional data are available.

Open Access This is an Open Access article distributed in accordance with the Creative Commons Attribution Non Commercial (CC BY-NC 4.0) license, which permits others to distribute, remix, adapt, build upon this work noncommercially, and license their derivative works on different terms, provided the original work is properly cited and the use is non-commercial. See: http:// creativecommons.org/licenses/by-nc/4.0/

\section{REFERENCES}

1. Centers for Disease Control and Prevention. National Diabetes Statistics Report: estimates of diabetes and its burden in the United States, 2014. Atlanta, GA: US Department of Health and Human Services, 2014

2. Coccheri S. Approaches to prevention of cardiovascular complications and events in diabetes mellitus. Drugs 2007;67:997-1026.

3. Alwakeel JS, Al-Suwaida A, Isnani AC, et al. Concomitant macro and microvascular complications in diabetic nephropathy. Saudi $J$ Kidney Dis Transpl 2009;20:402-9.

4. Cavanagh PR, Simoneau GG, Ulbrecht JS. Ulceration, unsteadiness, and uncertainty: the biomechanical consequences of diabetes mellitus. J Biomech 1993;26(Suppl 1):23-40.

5. American Diabetes Association. Economic costs of diabetes in the U.S. In 2007. Diabetes Care 2008;31:596-615.

6. American Diabetes Association. Economic costs of diabetes in the U.S. in 2012. Diabetes Care 2013;36:1033-46.

7. Menzin J, Langley-Hawthorne C, Friedman M, et al. Potential short-term economic benefits of improved glycemic control: a managed care perspective. Diabetes Care 2001;24:51-5.

8. Mabrey ME, McFarland R, Young SL, et al. Effectively identifying the inpatient with hyperglycemia to increase patient care and lower costs. Hosp Pract 1995 2014;42:7-13.

9. Nathan DM, Buse JB, Davidson MB, et al. Medical management of hyperglycemia in type 2 diabetes: a consensus algorithm for the initiation and adjustment of therapy: a consensus statement of the American Diabetes Association and the European Association for the Study of Diabetes. Clin Diabetes 2009;27:4-16.

10. Inzucchi SE, Bergenstal RM, Buse JB, et al, American Diabetes Association (ADA); European Association for the Study of Diabetes (EASD). Management of hyperglycemia in type 2 diabetes: a patient-centered approach. Position statement of the American Diabetes Association (ADA) and European Association for the Study of Diabetes (EASD). Diabetes Care 2012;35:1364-79.

11. Deyo RA, Cherkin DC, Ciol MA. Adapting a clinical comorbidity index for use with ICD-9-CM administrative databases. J Clin Epidemiol 1992;45:613-19.

12. Klabunde CN, Potosky AL, Legler JM, et al. Development of a comorbidity index using physician claims data. J Clin Epidemiol 2000;53:1258-67.

13. Chang HY, Weiner JP, Richards TM, et al. Validating the adapted Diabetes Complications Severity Index in claims data. Am J Manag Care 2012;18:721-6.

14. Rodondi N, Peng T, Karter AJ, et al. Therapy modifications in response to poorly controlled hypertension, dyslipidemia, and diabetes mellitus. Ann Intern Med 2006;144:475-84.

15. Barker LE, Kirtland KA, Gregg EW, et al. Geographic distribution of diagnosed diabetes in the U.S. Am J Prev Med 2011;40:434-9. 